\title{
EFFECTS OF THE APPLICATION PROGRAMME OF CORRECTIVE EXERCISES ON FOOT CONDITION
}

\author{
Slaviša Lazutai, \\ Nikolina Gerdijan², \\ Željko Vukić \\ 1i Elementary school "Jovan Cvijić" \\ Banja Luka, \\ Bosnia and Herzegovina \\ 2University of Banja Luka, \\ Faculty of Physical Education and Sports, \\ Republic of Srpska, \\ Bosnia and Herzegovina
}

\begin{abstract}
:
The aim of this study was to determine the effects of corrective exercise programmes on the foot condition. The research was attended by 66 subjects (students of the Jovan Cvijic elementary school, Banja Luka) aged 11-12 years. Of the total number of subjects on initial testing, 44 subjects $(72.7 \%)$ had flat foot deformity (first, second and third degree) and they participated in further research. The Footplate currex platform was used to assess the arch of the foot. The programme of flat foot corrective exercises lasted a total of 4 months. Exercises were performed twice a week for 20 minutes. The programme included a total of 13 exercises and each exercise was repeated 20 times. A Chi-squared test was applied to determine if there was a difference in the frequency of foot deformities between the initial and final measurements, as well as gender differences, i.e. whether the applied exercise programme affected the reduction of foot arch deformity $(p<0.05)$. The obtained results showed a statistically significant difference between the initial and final measurement $(p=0.008)$. At the initial measurement, most subjects had the first degree of flat foot deformity (33 subjects or 75\%), the second degree (9 subjects or $20.50 \%$ ), and the third degree ( 2 subjects or $4.50 \%$ ). Corrective exercises had positive effects in subjects with the established first-degree flat foot deformity. After the programme of corrective exercises, the deformity of the first degree disappeared in 10 subjects $(22.7 \%)$. In subjects with established foot deformities of the second and third degree, no statistically significant difference was observed after the programme of corrective exercises. By analysing the statistically obtained data of flat foot deformities between male and female subjects, we concluded that there is a higher number of deformities in
\end{abstract}

${ }^{i}$ Correspondence: email slavisa80@yahoo.com 
boys, although the result has no statistical significance. Based on the data, we can conclude that exercises are the most effective method for flat foot correction. If there is a higher degree of foot deformity, it is necessary to perform corrective exercises for a longer period of time and with a stronger intensity (several times a week).

Keywords: corrective exercises, flat foot, deformity

\section{Introduction}

One of the most common deformities in preschool and school age children is flat foot deformity that occurs as a result of hypokinesia. In practice, different exercise programmes are most often used in order to prevent various deformities, including foot deformities. Foot function is very important in maintaining the stability and necessary amortisation of the entire locomotor system. According to Rose (2007), a flat foot is the most common phase disorder of postural status in young school children. There are three phases of development of flat foot deformity depending on the level of anatomical and functional changes of the locomotor system of the foot. In relation to the etiology of foot deformities, they can be congenital and acquired (Lazuta, 2020). Congenital flat foot is an extremely severe deformity as a consequence of pathological changes in the ankle bone. It occurs very rarely, and changes occur in the embryonic development itself as a result of certain rickets disorders, which contribute to bone changes. Acquired factors that contribute to the development of a flat foot are: excessive obesity in the developmental age of the child, rickets and rickets disorders, atonicity or flaccidity of some muscle groups of the lower leg or foot, various mechanical injuries or diseases, physical inactivity, hygiene (Bordin, Giorgi, Mazzocco \& Rigon, 2001; Milenković, 2007). According to Staheli, Chew \& Corbett (1987), the process of anatomical formation of the longitudinal arch of the foot develops during the first decade of life, during which it is raised. In that period, certain irregularities in the structural status of the arch of the foot are already noticed, which are significantly different from the regular foot. Throughout life, a person's foot undergoes changes, and the most critical period is the period of rapid growth of the child and the period of puberty when there are sudden hormonal changes in the body (growth and weight gain).

According to Brooks (1991), a flat foot in early childhood is considered normal (97\% one-year-olds, $54 \%$ three-year-olds), with a tendency to fall to $24 \%$ in six-year-olds (Pfeiffer, Koty, Ledl, Hauser \& Sluga, 2006). The formation of normal physiological arches ends in the seventh year, so that in ten-year-olds only about $5 \%$ have lowered feet (Vukašinović, Živković and Vučetić, 2009).

Numerous studies have been conducted on different populations dealing with functional and anatomical analysis of foot status. Mihajlović, Smajić, \& Sente (2010) in a sample of 272 girls, aged 4 to 7 , analysed the occurrence of deformities depending on age. The obtained results confirmed about $90 \%$ of the deformities, but they also found that with age the deformities decrease (they take an inverse relationship), while the formation of the arch of the foot lasts until school age, and not with 4 years of age. Children who 
walk earlier have a risk factor for developing foot deformities (Pfeiffer et al. 2006) as well as children who are hypermobile and obese (Rose 2007; Dowling, Steele, Baur, 2001). Kosinac and Kukalas (1988) believe that foot deformity in higher grades in boys decreases while in girls it increases, which is contrary to the results of research by a group of authors (Garcia-Rodriguez, Martın-Jiménez, Carnero-Varo, Gómez-Gracia, Gómez -Aracena, \& Fernández-Crehuet, 1999). Hodžić, Mikić, Gerdijan, \& Bratovčić (2010) assessed the foot status of 166 children aged 8-9 years, divided into two groups. The obtained results show the absence of statistically significant differences in the occurrence and distribution of foot deformities, with regard to the sex of the subjects, as well as the differences between the left and right foot. Most of the samples have changes in the foot of the first degree. It is recommended that further progression of this deformity can be prevented by programmed exercise and education of subjects and their parents, and by the consulting role of teachers.

Research of Bjeković, Gerdijan, Ilić, \& Arnaut (2011) determines the actual parameters of frequency and degree of foot deformity in preschool children and possible differences in the prevalence of this deformity between the sexes. The results of the research indicate the existence of a relatively large percentage of deformities of the longitudinal and transverse arch of the foot, and the fact that there is a statistically significant difference in the prevalence of foot deformities between the sexes, with a higher prevalence in girls. In both sexes, the largest percentages of deviations from the physiologically correct arch of the foot are functional disorders, which can be successfully corrected with appropriate measures. The earlier entry of girls into puberty explains the higher prevalence of flat feet at a younger age, in contrast to boys, in whom puberty begins somewhat later, and accordingly most disorders occur in older age. A similar study is conducted by Jovović, \& Čanjak (2010) on a sample of 251 subjects aged 10, 12 and 14 years, with the aim of determining the frequency of flat feet depending on age. The obtained results show that the highest frequency of disorders is present in boys aged 14 years (30\%) and girls aged 12 years (31.5\%). Pain as a consequence of poor functional status of the feet can occur in adolescence, but also not manifest itself until adulthood. It occurs as a consequence of compensating for the disturbed stato-dynamic relationship in the feet; a chronic feeling that the footwear is tight because the longitudinal arch has descended; chronically cold feet; pain in the area of the ankles and varicose veins in the lower legs, due to the inability of the muscles to expel venous blood towards the heart (Živković, 2000). Physical activity is increasingly recognised as an important component of primary disease prevention. Adolescent athletes, as well as adults, are prone to bad form, habits and inappropriate implementation of the training process. In addition, the anatomical shape of the hind, middle, and forefoot can make athletes prone to specific injuries (Kennedy, Knowles, Dolan \& Bohne 2005). The shape and function of the feet can influence the occurrence of injuries (Kaufman, Brodine, Shaffer, Johnson \& Cullison, 1999), and the resulting injuries can end in the cessation of these activities of athletes (Razeghi \& Batt, 2000). 
The existence of a flat foot disrupts the statics of the whole body, it is difficult to walk and perform daily motor activities (Antičević 2000; Harris, Vanore, Thomas, Kravitz, Mendelson, Mendicino, Gassen, 2004; Ciliga, Trošt-Bobić, \& Filipović, 2014).

Some authors (Lizis, Posadzki, Smith, 2010; Espinosa 2010, Aleksandrović, Kottaras, 2015) believe that most people with flat feet have no problems during life due to this deformity and that a flat foot does not negatively affect motor efficiency (explosiveness and balance), and it is not a limiting factor for playing sports. Some studies (Nigg, Cole \& Nachbauer (1993) analyse the functional relationship between foot arch height and injuries related to the frequency of running injuries. Using the threedimensional kinematic research method, the values of lower extremity variables during running were determined. The common coordinate system was used to calculate the three-dimensional orientation of the ankle joint in one phase of the running step. Injuries were found to increase statistically significantly with increasing foot arch height. The authors also point out the existence of other factors, not only the height of the arch of the foot, which are related to the etiology of knee pain. Zivkovic, Petrovic and Petkovic (1991) are researching the possible connection between a flat foot and static balance. The obtained results are in accordance with their assumption about the statistical significance of the status of the feet for this motor ability. The higher the percentage of arched disturbance in the foot deformity, the lower the results of the static balance assessment tests. The research conducted on a sample of children aged 11 to 15 years (Tudor, Ružić, Sestan, Sirola and Prpić, 2009) did not confirm the connection between the degree of lowering of the feet and certain motor abilities necessary to achieve good sports results. Moreover, it was not found that children with flat foot deformity achieved poorer results compared to children with normal physiological arch of the foot. Children with flat and children with 'normal' arch of the foot were equally successful in fulfilling all motor tests. The authors point out that there is no need to correct the deformity of flat feet with the sole goal of improving sports results and achievements, which is the traditional advice of many other authors, because sometimes people with flat feet have better results than people with a normal arch (Živković, Živković, Bubanj, Milenković, Karaleić and Bogdanović (2014). It is a known fact that adequate application of preventive and corrective exercises plays a major role in the formation of a proper foot, and exercise was and is the most powerful means of preventing the occurrence of deformities and eliminating existing deformities. Many authors have dealt with the effects of corrective foot exercises on children of different ages.

Kolooli, Mahdavi-Nezhad, \& Mirnosuri (2014) observed the effects of a two-month programme of corrective exercises on a sample of students aged 12 to 16 years, divided into control and experimental groups. After 18 treatments lasting 60 to 80 minutes the results show a statistically significant difference before and after the programme for the experimental group and not for the control one. The authors conclude that the application of corrective exercises can improve the flat foot. The effects of corrective exercises on the flat foot of preschool children are investigated by Stanišić, Đorđević, \& Maksimović (2014). The sample included 60 children of both sexes, the postural status of the legs was determined by the method of Napoleon Wolanski, the degree of lowering of the arch of 
the foot was estimated using a plantogram (Tomsen's method). The corrective program of foot exercises lasted 2 months; the exercises were performed 3 times a week for 60 minutes. The obtained results confirm a positive but not statistically significant effect on the status of the feet. Sivachandiran and Vinod-Kumar (2016) define the impact of corrective exercise programmes on a flat foot as the main goal of the research. 550 athletes participated in the research, and the obtained results showed that 78 subjects have flat feet. Subsequently, 40 subjects proceeded to further research (20 made up the experimental group and 20 the control group). The experimental group had corrective exercises 5 times a week for 1 hour (10 minutes of warm-up, 40 minutes of corrective exercises and 10 minutes of stretching). The exercise programme lasted 12 weeks. The control group did not apply a programme of corrective exercises. The variables observed were the angle of the arch of the foot, the navicular height and the internal longitudinal arch. A pedograph was used to assess the arch of the foot. The results for the experimental group showed that a 12-week program of corrective exercises contributed to a statistically significant improvement in the variable foot arch angle, navicular height, and internal longitudinal arch.

The effects of programmed kinesiological treatment for the correction of flat feet and kyphosis of students are being investigated by Mikić, Bajrić, Čerkez - Zovko, Pehar, \& Stankovska (2019). On a sample of 290 students aged 9 to 11 years, they applied a programme of corrective exercises for flat feet and kyphosis for one school year. The programme consisted of 10 exercises where each exercise was repeated 10 times, in the scope of 3 times a week for two teaching hours. The obtained results showed changes of the first degree of deformation on the arches of the feet and the spinal column. After the applied kinesiological treatment for one school year, the authors confirm the positive effects on the correction of both deformities, with more significant effects in foot deformities compared to spinal deformities.

Nikšić (2016) examines the frequency of student deformities in relation to gender as well as the effects of the application of elementary games intended for the prevention and correction of impaired arch of the foot. On a large sample of over 1100 subjects of both sexes, aged 5 to 12 years, the assessment of the arch of the foot was performed by the plantography method, and the index of the arch of the foot was determined on the basis of the Thomsen method. The obtained results confirm the differences between the sexes in the initial and final measurement in terms of the degree of foot deformity. In the final measurement, girls have a higher representation of second-degree deformities and boys a higher representation of first-degree deformities, although the difference is not statistically significant but retains the inverse trend compared to the initial measurement. Research by Riccio, Gimigliano, Gimigliano, Porpora, \& Iolascon (2009) compares a group of children ( 3 to 8 years of age) who followed a rehabilitation exercise programme with a group of children who were treated with insoles and orthopedic footwear. The feet were classified according to Viladot's method with a rehabilitation programme of simple corrective exercises lasting 3 times a week for 2 hours. The results showed that of the 386 type III feet, 22 feet remained at the same degree of deformity, 12 feet went into grade II, and $86.6 \%$ of the feet became normal. Of the 214 grade II feet, $98.1 \%$ became 
normal. Comparing the success rate (changes from type III and II to I or normal) in both groups of children, the authors concluded that the rehabilitation program was more effective.

The results of other research (Shahrivar, Sokhanguel, \& Behboodi, 2014) show that wearing insoles simultaneously with a programme of corrective exercises has statistically significant positive effects on balance, agility, speed, muscle strength and endurance. A similar study in the experimental and control group was conducted by Kim and Kim (2016) examining the impact of corrective exercises and wearing insoles on improving the internal longitudinal arch and dynamic balance in people with flat feet. The experimental group performed short corrective foot exercises and the control group used insoles specially made for each subject. The program lasted a total of 5 weeks, 3 times a week for 30 minutes for both groups. The results showed that sensory motor training such as short corrective exercises had better effects than conservative treatment such as arch support with the use of insoles.

Based on the previously presented research as well as the obtained results, a current research was conducted with the aim of determining and analysing the effects of the application programme of corrective exercises on the condition of the feet of students aged 11 and 12 .

\section{Method}

The research of a longitudinal character was performed on a sample of 44 students of the 6th grade of the Jovan Cvijić elementary school in Banja Luka, aged 11 and 12, both sexes. Testing was performed on a foot platform (Currex footplate, Gmb Germany) in a private clinic Sport studio, Banja Luka. In a very simple and fast way, a computer analysis of the statics and dynamics of the foot obtained precise data on the function and development of the foot, data on the surface of each part of the foot, as well as the ratio of the back and front of the foot. Depending on the pressure, i.e. the color distribution, the status of the foot is classified into: normal, concave, dissipated and I, II, III and IV degree of flat foot (Jovović, 2008).

\subsection{Description of experimental treatment}

The programme of corrective exercises lasted a total of 4 months, twice a week in the physical education class, at the beginning of the class, after the introductory-preparatory part of the class. A total of 13 exercises of 20 repetitions were performed, which took a total of 20 minutes. All subjects, regardless of the degree of deformity, performed the same exercises. The props used during the exercises are: balls, tennis balls, pull rope, relay sticks, plastic cups and terry towels of smaller dimensions. After completing a fourmonth cycle of exercises to correct the deformity of the arch of the foot, re-final testing was performed, after which we obtained data on the impact of corrective exercises on the foot by statistical data processing, comparing the results of initial and final measurements. The programme of corrective exercises for the flat foot in this research was applied on the basis of professional literature in the field of kinesitherapy, where 
some of the exercises are used in ballet and Pilates as preparatory exercises for training (Ivanović, 2009).

The obtained data were processed using the statistical program SPSS 20. The results of the assessment of foot deformity are presented using frequencies by individual categories, and testing of the differences between the initial and final measurements was performed using the Chi-squared test.

Table 1: Programme of corrective exercises for correction of foot deformities (Ivanović, 2009)

\begin{tabular}{|c|c|c|c|}
\hline No. & Exercise Description-Exercise Method & $\begin{array}{l}\text { Number of } \\
\text { series }\end{array}$ & $\begin{array}{l}\text { Number of } \\
\text { repetitions }\end{array}$ \\
\hline 1. & $\begin{array}{l}\text { Starting position standing, lift the heel and lean } \\
\text { on the front of the foot, then bend the toes and } \\
\text { lean on the upper part of the foot. }\end{array}$ & 1 & 20 \\
\hline 2. & $\begin{array}{l}\text { Starting position standing, lean on your heel and } \\
\text { pull the towel towards you with the front of your } \\
\text { foot. }\end{array}$ & 1 & 20 \\
\hline 3. & $\begin{array}{l}\text { Starting position standing, lean on the whole foot } \\
\text { and pull the toes towards the heel. }\end{array}$ & 1 & 20 \\
\hline 4. & $\begin{array}{l}\text { Starting position standing, bend the toes towards } \\
\text { the heel and apply alternating pressure from the } \\
\text { little toe to the big toe and vice versa, then raise } \\
\text { the toes and repeat the exercise in the same } \\
\text { order. }\end{array}$ & 1 & 20 \\
\hline 5. & $\begin{array}{l}\text { Starting position standing, walk on your toes } \\
\text { with your heel turned inwards. }\end{array}$ & 1 & 20 \\
\hline 6. & $\begin{array}{l}\text { Starting position standing, grasp and release the } \\
\text { towel with your toes alternately. }\end{array}$ & 1 & 20 \\
\hline 7. & $\begin{array}{l}\text { Starting position standing, grab the glasses with } \\
\text { your toes and stack them into each other. }\end{array}$ & 1 & 20 \\
\hline 8. & $\begin{array}{l}\text { Starting position standing, walk sideways on a } \\
\text { rope. }\end{array}$ & 1 & 20 \\
\hline 9. & Starting position sitting, roll the ball with the sole & 1 & 20 \\
\hline 10. & $\begin{array}{l}\text { Starting position sitting, bend your toes down } \\
\text { and circle from right to left, then lift and spread } \\
\text { your toes and circle from left to right. }\end{array}$ & 1 & 20 \\
\hline 11. & $\begin{array}{l}\text { Starting position sitting, roll the stick with the } \\
\text { outer and then inner side of the soles }\end{array}$ & 1 & 20 \\
\hline 12. & $\begin{array}{l}\text { Starting position sitting, with the toes and the } \\
\text { front of the sole of one foot slide from top to } \\
\text { bottom on the inside of the other foot. }\end{array}$ & 1 & 20 \\
\hline 13. & $\begin{array}{l}\text { Starting position sitting, bend the legs at the knee } \\
\text { and embrace the ball with the inside of the sole, } \\
\text { then stretch the legs. }\end{array}$ & 1 & 20 \\
\hline
\end{tabular}

\section{Results}

The obtained research results are presented as a percentage through the frequencies of individual categories, i.e. the degree of deformity. A Chi-squared test was applied to 
determine if there was a difference in the frequency of foot deformities between the initial and final measurements, as well as gender differences, i.e. whether the applied exercise programme had an effect on reducing the frequency of foot arch deformities $(p<0.05)$.

Table 2: Numerical representation of the condition of the arch of the foot in the initial final measurement

\begin{tabular}{|l|c|c|c|c|c|}
\hline \multirow{2}{*}{ Measurement } & $\begin{array}{c}\text { Physiologically correct foot } \\
\text { (no. of entities) }\end{array}$ & \multicolumn{3}{|c|}{ Deformity degree } & \multirow{2}{*}{ Total } \\
\cline { 3 - 5 } & 18 & I & II & III & \\
\hline \multirow{2}{*}{ Initial } & $(27,3 \%)$ & 37 & 9 & 2 & $66(100 \%)$ \\
& 10 & $(56,1 \%)$ & $(13,6 \%)$ & $(3 \%)$ & \\
\hline \multirow{2}{*}{ Final } & $(22,7 \%)$ & 23 & 9 & 2 & $44(100 \%)$ \\
& $(52,3 \%)$ & $(20,5 \%)$ & $(4,5 \%)$ & \\
\hline
\end{tabular}

Table 3: Difference in degrees of deformity between initial and final measurement

\begin{tabular}{|c|c|c|c|c|c|}
\hline \multirow{2}{*}{ Measurement } & \multicolumn{4}{|c|}{ Deformity degree } & \multirow{2}{*}{ Total } \\
\hline & 0 & I & II & III & \\
\hline Initial & $\begin{array}{c}0 \\
(0 \%) \\
\end{array}$ & $\begin{array}{c}33 \\
(75 \%) \\
\end{array}$ & $\begin{array}{c}9 \\
(20,50 \%) \\
\end{array}$ & $\begin{array}{c}2 \\
(4,5 \%) \\
\end{array}$ & $\begin{array}{c}44 \\
(100 \%) \\
\end{array}$ \\
\hline Final & $\begin{array}{c}10 \\
(22,70 \%)\end{array}$ & $\begin{array}{c}23 \\
(52,30 \%)\end{array}$ & $\begin{array}{c}9 \\
(20,50 \%)\end{array}$ & $\begin{array}{c}2 \\
(4,50 \%)\end{array}$ & $\begin{array}{c}44 \\
(100 \%) \\
\end{array}$ \\
\hline
\end{tabular}

Note: $\chi 2$ - Chi-squared statistics; df-degrees of freedom; $p$-level of significance

Table 4: Difference in the degree of deformity between the sexes at the initial and final measurement

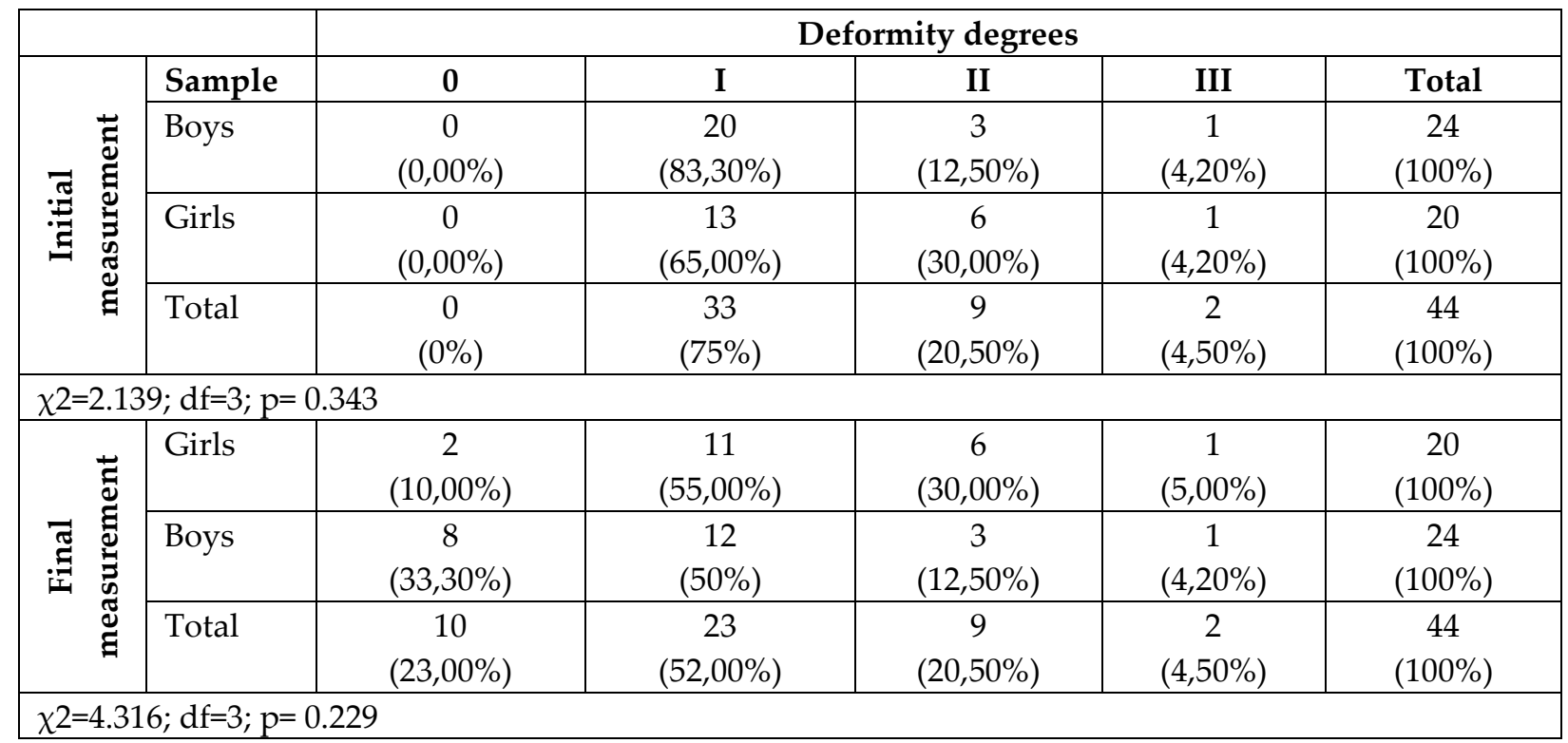

Note: $\chi 2$ - Chi-squared statistics; df-degrees of freedom; $p$-level of significance

The presented distribution of the results of the initial and final measurement of the total sample (Table 2 ) was recorded by only $27.3 \%$ of subjects with a physiologically correct foot, while grade I deformity was recorded in 56\%, grade II $13.6 \%$ and grade III $3 \%$ of subjects at the initial measurement. In the final measurement of the total sample (44 
entities) that underwent corrective treatment, $22.7 \%$ of subjects had a normal physiologically correct foot, deformity I degree $52.3 \%$ of subjects, II degree $20.50 \%$ and III degree $4.50 \%$ of subjects. Continuing the inspection of the results (Table 3), it can be concluded that in the subjects in whom the initial measurement revealed a deformity of the feet of the II and III degree, after the programme of corrective exercises, there was no significant correction of the arch of the foot. The obtained results of the Chi-squared test (Table 4) did not record statistically significant differences between male and female subjects in terms of the presence of foot deformities at the initial measurement $(\chi 2=2.139$; $\mathrm{df}=3 ; \mathrm{p}=0.343$ ) as well as at the final measurement. $\chi 2=4.316 ; \mathrm{df}=2 ; \mathrm{p}=0.229$ ).

\section{Discussion}

The defined research was conducted on a sample of 44 sixth grade students, aged 11 and 12 , both sexes. Testing was performed on a foot platform (Currex footplate, Gmb Germany) in a private clinic Sport studio, Banja Luka in order to determine whether the applied programme of corrective exercises for the flat foot influences the improvement of the status of the feet in boys and girls. By analysing the obtained data (Table 2), it can be noticed that at the initial measurement, out of the total number of students with deformities, the largest number of students had grade I deformity, while grade II and III deformities were less represented. Kosinac and Kukalas (1988) examined the status of the feet on subjects aged 6 to 10 years, and obtained the results of the frequency of deformities of the arch of the foot, i.e. the presence of flat foot in $58.9 \%$ of subjects. The authors Mihajlović, Šolaja, Petrović (2009) on a sample of 557 subjects of both sexes, aged 4 to 7 years, found that over $90 \%$ of students have unsatisfactory initial status of the feet and concluded that given the frequency of deformities at this age, one might conclude that this is a physiological formation of the foot and not a deformity. Sabo (2009) found $46 \%$ of lowered feet in a large sample of boys and girls aged 4 to 7 years. From Table 3 it can be seen that at the initial measurement most subjects had the first degree of deformity (33 subjects or $75 \%$ ), then the second degree ( 9 subjects or $20.50 \%$ ), while the smallest number of subjects had the third degree of deformity (2 subjects or $4.50 \%$ ). After the programme of corrective exercises in 10 subjects $(22.70 \%)$, the determined deformity of the arch of the foot disappeared, which tells us that corrective exercises have a significant effect on the correction of the arch of the foot. The number of subjects with first degree deformity, which was the most common at the initial measurement, significantly decreased in the final measurement, so 23 subjects had this degree of deformity (52.30\%).

Positive effects of corrective exercises on the correction of the arch of the foot have been proven by the authors Kolooli, et al. (2014), Mikić, et al. (2019), Sivachandiran and Vinod-Kumar (2016), as well as the authors Kim and Kim (2016) whose programme of corrective exercises lasted significantly shorter than others. They achieved positive results in just 5 weeks of exercise, 3 times a week for 30 minutes. Therefore, it is evident that performing corrective exercises, educating students and their parents, with good cooperation with teachers, is a sure way to correct the deformity of the arch of the foot, and it can certainly play a significant role in preventing deformities. This would include 
regular examinations of the arch of the foot at school, informing students and parents about the need for movement of children, as well as the negative impact of anatomically shaped insoles in footwear (which children usually wear) on the formation of a proper arch of the foot. A combination of daily exercises (Kim and Kim, 2016) for the correction of flat feet is recommended. Barefoot walking or walking in shoes without a factory insole or a subsequently inserted orthopedic insole is the correct way to form a good arch of the foot (Riccio et al., 2009) because in that case the complete locomotor apparatus engages and encourages the foot to hold itself and form a proper arch.

Otherwise, if we buy shoes for children with insoles, we give the central nervous system information (from getting up to sleep) that something is holding our arch of the foot, which will cause the muscles to lose their function and atrophy over time. Descriptively, it happens because the muscles do not need to act, which in our opinion is one of the most common causes of flat feet deformities. Based on the obtained data, we conclude that in case of a higher degree of flat foot deformity, it is necessary to perform corrective exercises for a longer period of time (eg 12 months) and stronger intensity (eg several times a week) as done by Riccio, Gimigliano, Gimigliano, Porpora, \& Iolascon (2009). Their research proved that it is possible to correct the arch of the foot from the third and second degree of deformity to a normal arch of the foot if the programme of corrective exercises lasts for a longer period of time. A Chi-squared test was used to determine if there was a difference between the initial and final measurements of the frequency of foot arch deformities. The obtained statistics amounted to 11.786 and for 3 degrees of freedom it was statistically significant $(p=0.008)$ at the significance level of 0.01. These data coincide with the research of the authors Kolooli, et al. (2014) as well as Mikić, et al. (2019). If we take into account the frequencies of certain categories of deformities, it can be concluded that this difference is caused by the fact that a number of subjects who had a first degree deformity at the initial measurement, after the programme of corrective exercises, this deformity disappeared. Table 5 shows that 44 subjects participated in the research, of which 24 were male and 20 were female. Firstdegree deformity was more prevalent in boys (83.30\%) than in girls (65\%). The difference is evident although it has no statistical significance. A higher number of deformities in boys than in girls coincides with the results of research by Jovović and Čanjak (2010); Garcıa-Rodriguez, Martın-Jiménez, etr al. (1999). Research indicates that boys have more problems with excess weight compared to school-age girls, especially between the ages of 7 and 15 (Jakšić \& et al., 2019; Milašinović \& et al., 2019), which may be the reason for more foot deformities in boys than in girls.

\section{Conclusion}

After the programme of corrective exercises for first degree deformities, significant progress was made, which ultimately resulted in 10 subjects or $22.7 \%$ losing the deformity. No progress was made in the second and third degree of deformity. Statistically processing the obtained data, we came to the conclusion that in the case of a higher degree of flat foot deformity, the chances of correction are lower with the applied 
programme of corrective exercises of 4 months. We believe that the correction of a flat foot of the second and third degree requires a longer time treatment, as done by Riccio et al. (2009). In the first degree of deformity correction is possible even when the exercise programme lasts less than 4 months (Kim and Kim, 2016). By analysing the statistically obtained data of flat foot deformity between male and female subjects, we concluded that there is a higher number of deformities in boys, although the result has no statistical significance. So, when we summarise everything, we come to the conclusion that exercises are the most effective method in correcting flat feet because exercises encourage muscles to give the foot a proper arch, constantly giving information to the central nervous system how the arch should look even when not in the exercise process. In this way, the central nervous system encourages the muscles to keep the foot in the correct position even when not in the process of exercising. The above said, obliges us, as physical education teachers, to regularly perform foot controls on students and, if we notice certain deviations, to give a suggestion to both students and parents, how and in what way they should act.

\section{Conflict of Interest Statement}

The authors declare no conflicts of interests.

\section{About the Authors}

Slaviša Lazuta is a master of Physical culture. He is employed as a professor of Physical education in elementary school "Jovan Cvijić" in Banja Luka. His research interests include program corrective exercise for the condition of the feet, swimming, ski.

Nikolina Gerdijan was born in Banja Luka in 1980. She is assistant professor at University of Banja Luka, Faculty of physical education and sport, Republic of Srpska, BIH. 2014 she acquired the title Doctor of Science in Physical Education and Sport by defending a thesis on "Acute effect of static and dynamic stretching on maximal force and power of thigh muscles". She is researching in the field of kinesiotherapy, injury prevention, isokinetic, postural balance, movement analysis, pilates.

Željko Vukić is assistant professor at University of Banja Luka, Faculty of physical education and sport, Republic of Srpska, BIH. His research interests include human movement in physical education, sport and recreation. Also, a member of the scientific advisory board at Foundation for Global Community Health.

\section{References}

1. Aleksandrović, M., \& Kottaras, S. (2015). Does the Precondition for Drooping Arch of the Feet Diminish Explosive Leg Strength: a Pilot study. Facta universitatisseries: Physical Education and Sport, 13(2), 303-309.

2. Antičević, D. (2000). Three the most common causes of the hip joint disorders in iuvenile and adolescent children. Paediatria Croatica. Supplement, 44(S1), 183-188. 
3. Bjeković, G., Arnaut, Đ., Gerdijan, N. (2011). Foot deformities in preschool children in the Nova radost kindergarten - East Sarajevo. Sport Mont IX (31-32-33), 48-52.

4. Bordin, D., De Giorgi, G., Mazzocco, G., Rigon, F. (2001). Flat and cavus foot, indexes of obesity and overweight in a population of primary-school children. Minerva Pediatrica, 53 (1), p. 7-13.

5. Brooks, M H.(1991). Flat feet in children. BMJ 1991;302:237

6. Bubanj, R. (1997). Basics of application of biomechanics in sports. Faculty of Philosophy: Niš.

7. Ciliga, D., Trost-Bobic, T. T., \& Filipović, B. (2014). Effect of fatigue on dynamic balance in different directions. In 7th International Scientific Conference on Kinesiology (p. 27).

8. Dowling, A. M., Steele, J. R., \& Baur, L. A. (2001). Does obesity influence foot structure and plantar pressure patterns in prepubescent children? International journal of obesity, 25(6), 845.

9. Đurašković, R. (2002). Sports medicine. Sven: Niš.

10. Espinosa, N., Brodsky, J. W., \& Maceira, E. (2010). Metatarsalgia. JAAOS-Journal of the American Academy of Orthopaedic Surgeons, 18(8), 474-485.

11. Footplate currex. Available at: www.yumpu.com/en/document/view/12995665/currex-footplate-data-sheet-pdf [accessed on February 27, 2020].

12. Garcia-Rodriguez, A., Martın-Jiménez, F., Carnero-Varo, M., Gómez-Gracia, E., Gómez-Aracena, J., \& Fernández-Crehuet, J. (1999). Flexible flat feet in children: a real problem? Pediatrics, 103 (6), p.84-84.

13. Harris, E. J., Vanore, J. V., Thomas, J. L., Kravitz, S. R., Mendelson, S. A., Mendicino, R. W.\& Gassen, S. C. (2004). Diagnosis and treatment of pediatric flatfoot. The Journal of foot and ankle surgery 43(6), 341-373.

14. Hodzic, Z., Mikic, B., Gerdijan, N., Bratovcic, V. (2010). Analysis of the status of the feet of students aged 8 to 9 years. Sports logos $8(14,15), 30-33$.

15. Ivanjicki, M. F. (1956). Anatomy of human. Phys. and Sports: Moscow.

16. Ivanovic, M. (2009). Flat feet in children. Valjevo-print: Valjevo

17. Jaksic, M., Martinovic M., Gligorovic- Barhanovic, N., Vujacic, A., Djurovic, D., Nedovic-Vukovic (2019). Association between inflammation, oxidative stress, vitamin $\mathrm{D}$, copper and zinc with pre-obesity and obesity in school children from the city of Podgorica, Montenegro. Journal of Pediatric Endocrinology and Metabolism 32 (9), 951-957.

18. Jovović, V, Čanjak, R. (2010). Flat foot frequency in children of different ages. Faculty of Philosophy: Nikšić.

19. Jovovic, V. (2008). Corrective gymnastics with kinesitherapy. Faculty of Philosophy: Nikšić.

20. Kaufman, K., Brodine, S., Shaffer, R., Johnson, C., Cullison, C. (1999). The effect of foot structure and range of motion on musculoskeletal overuse injuries. Am J Sports Med, 27 (5), p.585-593. 
21. Kennedy, J., Knowles, B., Dolan, M., Bohne, W. (2005). Foot and ankle injuries in the adolescent runner. Current Opinion in Pediatrics, 17 (1) p.34-42. New York.

22. Kim, E.K., and Kim, J.S. (2016). The effects of short foot exercises and arch support insoles on improvement in the medial longitudinal arch and dynamic balance of flexible flatfoot patients. Journal of Phys Ther Sci 28(11), p. 3136 -3139.

23. Kolooli, M., Mahdavi-Nezhad, R., \& Mirnosuri, R. (2014). The Effects of an 8-Week Corrective Exercise. Program on the Navicular Height of Teens with Flat Feet. Asian J of Multidisciplinary Studies 2 (5), p.96-99.

24. Kosinac, Z., Kukulas, R. (1988). Transvesal analysis of foot status in students aged 6-10 years. Physical Culture, 3, 111-113

25. Lazuta. S. (2020). Effects of corrective exercise programs on foot condition. Master's thesis. University of Banja Luka, Faculty of Physical Education and Sports.

26. Leung, A.K.L., Mak, A.F.T., Evans, J.H. (1998). Biomechanical gait evaluation of the immediate effect of orthotic treatment for flexible flat foot. Prosthetics and Orthotics International, 22 (1), p. 25-34.

27. Lieberman, D., Venkadesan, M., Werbel, W., Daoud, A., Andrea, S., Davis, I., Ojiambo Mang'Eni, R., Pitsiladis, Y. (2010). Foot strike patterns and collision forces in habitually barefoot versus shod runners. Nature, 463, p. 531-535.

28. Lizis, P., Posadzki, P., \& Smith, T. (2010). Relationship Between Explosive Muscle Strength and Medial Longitudinal Arch of the Foot. Foot $\mathcal{E}$ Ankle International, 31(9), 815-822.

29. Mihajlović I., Šolaja M., Petrović M. (2010). Foot deformities in preschool children in relation to gender and age. Glasnik Antropoloskog drustva Srbije 45, 475-481.

30. Mihajlović, I., Smajić, M., Sente, J. (2010). Frequency of foot deformities in preschool girls. Military Medical Review 6 (11), 928-932.

31. Mikic, B., Bajric, S., Cerkez-Zovko, I., Pehar, M. and Stankovska, Z. (2019). Effects of programmed kinesiological treatment on the correction of kyphosis and flat foot deformities in students. Sports Science and Health 9 (2), 92-101

32. Milašinović, R., Bojanić, D., Čvorović, A., \& Kukić, F. (2019). Age and gender difference in nutritional status of school children according to WHO, CDC and IOTF references: A statewide study from Montenegro. Sport Mont, 17(1), 15-21.

33. Milenkovic S. (2007). Corrective gymnastics - theory and exercise. Faculty of Philosophy: Nis.

34. Nigg, B.M., Cole, G.K., Nachbauer, W. (1993). Effects of arch height of the foot on angular motion of the lower extremities in running. J Biomech. 26 (8), p. 909-916.

35. Niksic, E. (2016). Frequency of foot deformities in primary school students in relation to gender. International Scientific Conference InSSED, collection of papers 1 (1), 53-61..

36. Pfeiffer, M., Koty, R., Ledl, T., Hauser, G., Sluga, M. (2006). Prevalence of flat foot in percolated children. Pediatrics. 118 (2), 634-639.

37. Razeghi M., Batt, M.E. (2000). Biomechanical analysis of the effect of orthotic shoe inserts: a review of the literature. Sports Medicine, 29 (6), 425-438. 
38. Riccio, I., Gimigliano, F., Gimigliano, R., Porpora, G., \& Iolascon, G. (2009). Rehabilitative treatment in flexible flatfoot: a perspective cohort study. Chir Organi Mov. 93 (3):101-7.

39. Rose, C.R.E. (2007). Flat feet in children: When should they be treated? The Internet Journal of Orthopedic Surgery, 6, 1

40. Sabo, E. (2008). The shape of the legs and the posture of the feet of preschool children in Novi Sad. Pedagogical reality, 54 (1-2), 108-113.

41. Shahrivar, M.F., Sokhanguei, Y., and Behboodi, L. (2014). The Effect of Insole with Corrective Exercises on some of Physical andMotor Fitness Factors in Girls with Flat Foot. European Journal of Experimental Biology 4(1), p.534-537.

42. Sivachandiran, S., and Dr. Vinod Kumar, G. (2016). Effect of corrective exercises programme among athletes with flat feet on foot alignment factors. International Journal of Physical Education, Sports and Health; 3(6): 193-196.

43. Staheli, L.T., Chew, D.E., Corbett, M. (1987). The longitudinal arch. A survey of eight hundred and eighty-two feet in normal children and adults. The Journal of Bone and Joint Surgery, 69 (3), p.426-428.

44. Stanišić, I.R., Đorđević, M.M., Maksimović, S.Z. (2014). Postural status of the feet in preschool children and the effects of corrective exercise within targeted activities. Sinteze-Journal of Pedagogical Sciences, Literature and Culture, vol. 3, no. 5, p. 63-71.

45. Stanković, Lj. (2009). Watch me grow. Youth and Play Association: Subotica.

46. Tudor, A., Ružoć, L., Sestan, B., Sirola, L., Prpić, T. (2009). A flat foot is not a lack of athletic performance in children aged 11 to 15. Pediatrics 123 (3), 386-392.

47. Vukasinovic, Z., Zivkovic, Z., \& Vucetic, C. (2009). Flat feet in children. Serbian archive for all medicine, 137(5-6), 320-322.

48. Whitford, D, Esterman, A. (2007). A randomized controlled trial of two types of in-shoe orthoses in children with flexible excess pronation of the feet. Foot Ankle Int. 28, 715-723.

49. Yeung, S.S., Yeung, E.W., Gillespie, L.D. (2011). Interventions for preventing lower limb soft-tissue running injuries. Cochrane Database of Systematic Reviews 7, CD001256. DOI: 10.1002/14651858.CD001256.pub2.

50. Zivkovic M., Zivkovic, D., Bubanj, S., Milenkovic, S., Karaleic, S., \& Bogdanovic, 3. (2014). The dependence of explosive strength and speed on feet posture. Health $M E D, 235,246-252$.

51. Zivkovic, D. (2000). Theory and methodology of corrective gymnastics. Independent author's edition: Nis.

52. Zivkovic, D., Petrovic, M., Petkovic, D. (1991). The relationship between a flat foot and static balance. Ohrid: Serbia. 
Creative Commons licensing terms

Authors will retain the copyright of their published articles agreeing that a Creative Commons Attribution 4.0 International License (CC BY 4.0) terms will be applied to their work. Under the terms of this license, no permission is required from the author(s) or publisher for members of the community to copy, distribute, transmit or adapt the article content, providing a proper, prominent and unambiguous attribution to the authors in a manner that makes clear that the materials are being reused under permission of a Creative Commons License. Views, opinions and conclusions expressed in this research article are views, opinions and conclusions of the author(s). Open Access Publishing Group and European Journal of Physical Education and Sport Science shall not be responsible or answerable for any loss, damage or liability caused in relation to/arising out of conflict of interests, copyright violations and inappropriate or inaccurate use of any kind content related or integrated on the research work. All the published works are meeting the Open Access Publishing requirements and can be freely accessed, shared, modified, distributed and used in educational, commercial and non-commercial purposes under a Creative Commons attribution 4.0 International License (CC BY 4.0). 